Check for updates

Cite this: RSC Adv., 2017, 7, 20430

Received 28th February 2017 Accepted 24th March 2017

DOI: $10.1039 / \mathrm{c} 7 \mathrm{ra02506h}$

rsc.li/rsc-advances

\section{Safer-by-design hybrid nanostructures: an alternative to conventional titanium dioxide UV filters in skin care products $\dagger$}

\begin{abstract}
N. Shandilya (D) and I. Capron*
For sustainable development of nanotechnology, nanomaterials should follow a safer-by-design approach so that the associated exposure and hazard risks throughout their entire life cycle can be minimized without compromising their functioning efficiency. In this context, we present organic-inorganic hybrid nanostructures composed of titanium dioxide $\left(\mathrm{TiO}_{2}\right)$ nanoparticles grafted onto cellulose nanocrystals (CNC) using a sol-gel process. After grafting optimization, we show that the overall efficiency of these hybrid nanostructures to filter UV rays can be higher than their conventional counterparts. At the same time, these hybrid nanostructures are proven to stabilize Pickering emulsions, replacing surfactant in formulation. Hence, they may serve as an ideal alternative to the conventionally used inorganic filters and stabilizers in various applications such as skin care products.
\end{abstract}

\section{Introduction}

Rutile is one of the most common natural forms or polymorphs of titanium dioxide $\left(\mathrm{TiO}_{2}\right)$ occurring in nature. As compared with anatase (another common $\mathrm{TiO}_{2}$ polymorph), it has a high refractive index at ultraviolet and visible (UV-vis) wavelengths. During the interaction with $\mathrm{UV}$ rays, the free electrons on the rutile $\mathrm{TiO}_{2}$ nanoparticle (NP) surface oscillate and the UV absorption is blueshifted compared with anatase. ${ }^{1}$ Therefore, the rutile polymorph absorbs higher-energy UV light. Furthermore, when in physical contact with sensitive skins, rutile $\mathrm{TiO}_{2} \mathrm{NP}$ are not irritating and are highly compatible. For these reasons, they are widely used in skin care products as inorganic or mineral UV filters to protect against UV-induced skin damage. ${ }^{2-4}$

However, their use in skin care products is surrounded by many controversies. In the presence of water, oxygen and light, $\mathrm{TiO}_{2} \mathrm{NP}$ are well known to generate reactive oxygen species (ROS). Reports have suggested that NP in commercial sunscreens induce cyto- and genotoxicity through these ROS. ${ }^{5,6}$ Wu et al. ${ }^{7}$ concluded that $\mathrm{TiO}_{2} \mathrm{NP}$ could enter the deep layers of porcine epidermis as well as hairless mouse skin. In contrast, Zvyagin et al. ${ }^{8}$ and Kiss et al. ${ }^{9}$ showed that $\mathrm{TiO}_{2} \mathrm{NP}$ cannot penetrate the deep layers of healthy adult skin. Since the impact of NP on humans is dubious and poorly understood, clear regulations have not been implemented yet for NP by international authorities. Therefore, unless something is done to ensure $\mathrm{TiO}_{2} \mathrm{NP}$ become a completely safe ingredient, there will

Institut National de la Recherche Agronomique (INRA), UR 1268, Rue de la Géraudière, 44316 Nantes cedex 3, France. E-mail: isabelle.capron@inra.fr

$\dagger$ Electronic supplementary information (ESI) available. See DOI: $10.1039 / \mathrm{c} 7 \mathrm{ra02506h}$ be a need to decrease the amount of $\mathrm{TiO}_{2}$ to develop safer sunscreens.

The safer-by-design approach ${ }^{10-12}$ for synthesis of nanomaterials and product elaboration is useful regarding this concern. This pre-emptive approach aims to minimize the risks of nanomaterials during their entire life cycle (from manufacturing to end of life) through an intervention during product design phase. In other words, nanomaterials are conceived from the very start with an intention of having minimum environmental impact and human risk from their cradle to grave. However, the product benefits should not diminish while minimizing the risk. This approach has been used in the past too for different nanomaterials during their conception $^{13-17}$ as well as use phases. ${ }^{18-20}$ For instance, through a series of studies, Yan et al. ${ }^{13}$ showed that for the same nanomaterial, different preparation processes could induce different in vitro and in vivo toxic responses. Sotiriou et al. ${ }^{14}$ demonstrated that by hermetically encapsulating $\mathrm{ZnO}$ nanorods in a biologically inert nano-thin amorphous $\mathrm{SiO}_{2}$ coating during their gasphase synthesis, the earlier known risk of DNA damage can be lowered by three times without altering their optoelectronic properties. Damoiseaux et al..$^{15}$ introduced a high-throughput screening technique to rapidly identify nanomaterials' specific properties that can be modified during their conception phase in order to keep up with the safety assessment of abundantly produced novel nanomaterials. Demokritou et al. ${ }^{16}$ coated $\mathrm{CeO}_{2}$ $\mathrm{NP}$ by nanothin amorphous $\mathrm{SiO}_{2}$ encapsulation to mitigate their pulmonary toxicity to animals. Movia et al. ${ }^{17}$ showed that gelatincoated Au nanoboxes can efficiently deliver a chemotherapeutic agent to human lung adenocarcinoma (A549) cells, in contrast to the uncoated ones which may penetrate into A549 cells in simple or complex in vitro microenvironments. 
This work develops a different approach: we propose an in situ grafting of $\mathrm{TiO}_{2} \mathrm{NP}$ onto a bio-based product i.e. cellulose nanocrystals (CNC). CNC are unique organic nanorods derived from the most abundant and almost inexhaustible natural polymer - cellulose. Cellulose is a linear homopolymer of $\beta(1-$ 4)-D-glucose residues, found in nature as highly resistant fibers. ${ }^{21-23}$ CNC, obtained by acidic hydrolysis of the cellulose fibers, are biodegradable and renewable and hence they serve as a sustainable and environmentally friendly nanomaterial for a large variety of applications. ${ }^{24}$ They have nanorod-like structures that range from 70 to $1000 \mathrm{~nm}$ in length and 5 to $20 \mathrm{~nm}$ in width with high surface area to volume ratio, low density $\left(\approx 1.6 \mathrm{~g} \mathrm{~cm}^{-3}\right.$ ), a longitudinal Young's modulus in the range of 100-200 GPa and a reactive surface of $-\mathrm{OH}$ side groups that facilitates its grafting with different chemical species to achieve different surface properties. ${ }^{25,26}$

Once hydrolyzed, CNC are nanostructured since they have at least two dimensions below $100 \mathrm{~nm}$. As nanomaterials, they have received particular attention from a toxicological point of view. Although limited in number, studies have indicated CNC to show no significant environmental or human impact. ${ }^{28,29}$ For example, Endes et al. ${ }^{30}$ did not detect any significant cytotoxicity or oxidative stress induction or (pro)inflammatory responses in a multi-cellular in vitro test of the human epithelial airway barrier at the air-liquid interface for CNC suspensions with different concentrations, even up to the highest concentration of $1.57 \mu \mathrm{g} \mathrm{cm}^{-3}$. Ni et al. ${ }^{31}$ investigated the cytotoxicity of CNC dispersions to L929 cells by MTT (3-(4,5-dimethylthiazol-2-yl)2,5-diphenyltetrazolium bromide) assay and found no significant effect of different suspension concentrations ranging from $0.01 \%$ to $0.2 \%$. Hanif et $a .^{32}$ also shared a similar result in which they showed that the CNC do not reveal much cytotoxicity at various concentrations up to $250 \mu \mathrm{g} \mathrm{ml} \mathrm{m}^{-1}$. Hosseinidoust et $a l .{ }^{33}$ confirmed the biocompatibility of CNC by not detecting any damage or change in density of phagocytic and nonphagocytic cell lines during their interaction with CNC dispersions. Except for some studies ${ }^{34,35}$ that showed some minor detrimental effects for highly elevated CNC concentrations (>350 $\mathrm{mg} \mathrm{l}^{-1}$ ), CNC still remains a widely accepted versatile biomaterial for producing nature-friendly materials.

CNC is generally extracted from its native fibers through sulfuric acid hydrolysis; sulfuric acid reacts with the surface hydroxyl groups via an esterification process, allowing the grafting of anionic sulfate ester groups. ${ }^{21,22}$ The presence of these negatively charged groups induces the formation of a negative electrostatic layer and promotes excellent dispersion in water. ${ }^{25}$ This excellent aqueous dispersion of CNC remains intact even after functionalization. ${ }^{\mathbf{2 6 , 2 7}}$

In conventional skin care products like sunscreens, hand moisturizers, make up, etc., $\mathrm{TiO}_{2} \mathrm{NP}$ are usually added in excess to compensate for the poor aqueous dispersion of their industrial grades. Moreover, the majority of raw materials used during formulation are immiscible with each other and form an oil-in-water emulsion. An emulsion is commonly considered unstable if the droplets coalesce, thereby reducing the total interface area of the system. ${ }^{36}$ To stabilize the oil-water interfaces, surfactants are used which prevent the oil droplets from coalescing. However, a variety of surfactants are known to induce adverse effects such as irritation, interaction with biological membranes or foaming. ${ }^{37}$ As an alternative to these surfactant compounds, solid NP can be used as surfacestabilizing agents for an emulsion (i.e. Pickering emulsion). They are adsorbed at the oil-water interface and prevent the droplets from coalescing. ${ }^{38,39}$ This results in a highly stable emulsion. In this context, the CNC have already been tested on a large scale and shown to stabilize Pickering emulsions. ${ }^{38-43}$

Owing to the relative ease of grafting or immobilizing nanoparticles, there have been some studies in the past that have used native cellulose fibers or nanofibers as viable substrates for $\mathrm{TiO}_{2}$ grafting using various synthesis processes to impart photocatalytic properties to the composite. ${ }^{\mathbf{4 4 - 4 8}}$ The easy accessibility of these cellulose fibers has also made their use favorable. However, control of functionalization is more difficult owing to their complex structure (composed of amorphous and crystalline parts) and stabilization of emulsions in a welldefined way cannot be achieved via these fibers of length larger than the drop diameter. Hence, CNC serve as a better alternative to their native counterpart. In the present article, the in situ grafting of $\mathrm{TiO}_{2} \mathrm{NP}$ on $\mathrm{CNC}$ is realized using a sol-gel process. ${ }^{49}$ Its easiness, low temperature requirements, aqueous reaction medium and fast production justify the choice of solgel process in the safer-by-design context. We also show that by improving the net dispersion of $\mathrm{TiO}_{2} \mathrm{NP}$, via these hybrid organic/inorganic nanostructures, we can improve their UV absorbance as well as stabilize Pickering emulsions to render them surfactant-free i.e. same level of UV absorbance and Pickering emulsion stability with lesser amount of $\mathrm{TiO}_{2}$. The lesser amount of $\mathrm{TiO}_{2}$ used implies lesser potential toxicity concerns.

\section{Materials \& method}

\section{Chemicals}

For the experiments, we used pre-manufactured CNC which were provided by the Process Development Center at the University of Maine (Lot: 2015-FPL-CNC-071) at $12.2 \mathrm{wt} \% \mathrm{CNC}$ in water. For the synthesis of $\mathrm{CNC}^{-} \mathrm{TiO}_{2}$ hybrid nanostructures, an aqueous $\mathrm{CNC}$ dispersion was prepared by diluting the original gel to $5 \mathrm{~g} \mathrm{l}^{-1}$ concentration using de-ionized water and subsequent filtering using Millipore ${ }^{\circledR}$ membrane filters with 5 , 1.2 and $0.45 \mu \mathrm{m}$ mesh sizes. The analytical grade $\mathrm{H}_{2} \mathrm{SO}_{4}(1.83 \mathrm{~g}$ $\mathrm{ml}^{-1}$ specific gravity and $>95 \%$ purity) was provided by Fisher Scientific UK. The precursor used for the synthesis was titanium(Iv) oxysulfate $\left(\mathrm{TiOSO}_{4} ; \sim 15 \mathrm{wt} \%\right.$ in dilute sulfuric acid; $1.361 \mathrm{~g} \mathrm{~cm}^{-3}$ at $25{ }^{\circ} \mathrm{C} ; 495379$ Aldrich). Different Pickering emulsions were formulated using three different oils: $n$-hexadecane (0.773 $\mathrm{g} \mathrm{cm}^{-3}$ at $25{ }^{\circ} \mathrm{C}$; H0255 Sigma), coco-caprylate (Cetiol LC@; BASF SE, Germany) and isopropyl palmitate (Tegosoft® P; Evonik Nutrition \& Care GmbH, Germany).

\section{Sample preparation}

To synthesize $\mathrm{CNC}^{-\mathrm{TiO}_{2}}$ hybrid nanostructures, a sol-gel process was employed. Various volumes of sulfuric acid were 
added into $200 \mathrm{ml}$ of CNC suspension under vigorous stirring, followed by dropwise addition of titanium(Iv) oxysulfate. The mixture was then kept under constant stirring at different temperatures and for different durations. At the end of reaction, the resulting product was collected and further processed by repeated centrifugation and washing with distilled water to finally obtain a white precipitate or gel composed of $\mathrm{CNC}-\mathrm{TiO}_{2}$ hybrid nanostructures. Table 1 shows the experimental synthesis conditions. To formulate emulsions with hybrid nanostructures, a similar protocol was followed to that previously described in Kalashnikova et al. ${ }^{36}$ and Cherhal et al.:40 fourteen different emulsions (water/oil $=80 / 20$ ), each with a volume of $2 \mathrm{ml}$, were prepared with varying concentrations of $\mathrm{CNC}^{-\mathrm{TiO}_{2}}$ hybrid nanostructures in the aqueous phase from 0.048 up to $6 \mathrm{~g} \mathrm{l}^{-1}$. This was followed by sonication using intermittent pulses for 2 min for each emulsion with an ultrasonic device having a dipping titanium probe close to the surface. The sonication imparted milky white emulsions that were left for 2 days at room temperature. Contrary to Cherhal et al. ${ }^{\mathbf{4 0}}$ ionic strength had no impact on emulsion stability. So no salt was added to the emulsions as the presence of $\mathrm{TiO}_{2} \mathrm{NP}$ on the CNC already limited the repulsion due to negatively charged groups.

\section{Characterization}

$\mathrm{X}$-ray diffraction (XRD) spectra were recorded every $10 \mathrm{~min}$ on a Bruker D8 Discover diffractometer. $\mathrm{Cu}-\mathrm{K} \alpha_{1}$ radiation $\left(\mathrm{Cu} \mathrm{K} \alpha_{1}\right.$ $=1.5405 \AA$ ), produced in a sealed tube at $40 \mathrm{kV}$ and $40 \mathrm{~mA}$, was selected and parallelized using a Gobël mirror parallel optics system and collimated to produce a $500 \mu \mathrm{m}$ beam diameter. The data were collected in the $2 \theta=5-40^{\circ}$ range.

Thermogravimetric analysis (TGA) was carried out on a TGA 2050 (TA Instruments, France). The temperature was varied in the range $25^{\circ}$ to $900{ }^{\circ} \mathrm{C}$ by using a Platinel II ${ }^{\circ}$ thermocouple (Engelhard Industries). The heating rate was kept at $10{ }^{\circ} \mathrm{C}$ $\min ^{-1}$. The balancing resolution of the instrument is $0.2 \mu \mathrm{g}$ with a measurement accuracy of $\leq \pm 0.1 \%$. Since the hybrid $\mathrm{CNC}-\mathrm{TiO}_{2}$ nanostructures are in gel form, they were dried prior to thermogravimetric analysis. The gel (2 g) was cast over a Teflon-coated Petri dish inside a pre-heated oven at $40{ }^{\circ} \mathrm{C}$ for 60 to $90 \mathrm{~min}$. Once dried, the sample peels off in the form of a film. The percentage loss in mass of the dried sample was noted. The dried film was then ground, using a mortar, to obtain the powder for TGA.

For the microscopy, a JEOL JEM-1230 USA Transmission electron microscope (TEM) was employed operated at an accelerating voltage of $40 \mathrm{kV}$. Before microscopic analysis, the samples were prepared by depositing $\sim 20 \mu \mathrm{l}$ of a 10 -fold diluted dispersion onto a glow discharge carbon-coated electron microscope grid (200 mesh, Delta Microscopies, France) for 2 min. Excess solution was removed by blotting. Prior to deposition, the diluted dispersion was also sonicated for $1 \mathrm{~min}$.

The UV absorbance tests were done using a Specord ${ }^{\circledR}$ S 600 spectrophotometer (Ananlytik Jena AG, Germany). The instrument was controlled using modular Windows WinASPECT ${ }^{\circledR}$ software. Deuterium and halogen lamps were used as UVA and UVB irradiation sources. The detector in the spectrophotometer was allowed to capture the UV rays for $208 \mathrm{~ms}$ of integration time. To do the analysis, the aqueous suspensions were magnetically stirred for $10 \mathrm{~min}$ and sonicated using a dipping titanium probe for $2 \mathrm{~min}$, and finally the supernatant (in a quartz cuvette) obtained after centrifugation at $5000 \mathrm{rpm}$ for 5 min was irradiated. Irradiation of the supernatant is critical to filter out large colloidal particles (if any) in a suspension. These particles have a tendency to completely reflect the incident UV rays rather than absorbing them. A $200 \mathrm{~W}$ mercury-xenon lamp (4500 $\mathrm{mW} \mathrm{cm}^{-2}$ intensity at $365 \mathrm{~nm}$; Hamamatsu Lightning Cure LC8 UV Spot Light-source L9588) was used as UV exposure source.

Average droplet diameter, i.e. $D(3,2)$, in Pickering emulsions was measured by laser light diffraction using a Malvern 2000 granulometer apparatus equipped with a He-Ne laser (Malvern Instruments, UK).

The emulsions were visualized by an optical microscope (BX51, Olympus, France). A drop of the resulting Pickering emulsion was 10 times diluted using distilled water followed by vortex stirring. A single drop was then placed on a slide and visualized.

To obtain Infrared (IR) spectra, a Thermo Scientific Nicolet IS50 spectrometer was operated in transmission mode between 4000 and $400 \mathrm{~cm}^{-1}$. A $2 \mathrm{mg}$ powdered test specimen was ground with $120 \mathrm{mg}$ of $\mathrm{KBr}$ and compressed to obtain a thin pellet. Each IR spectrum was averaged automatically by the spectrometer over 200 scans.

\section{Results}

\section{Characterization}

The CNC used were negatively charged crystalline rod-like nanoparticles isolated from wood pulp by acid hydrolysis (Fig. 1). Their dimensions, as measured by TEM, were $160 \mathrm{~nm}$ in length and $6 \mathrm{~nm}$ in cross-section. The synthesis process of $\mathrm{TiO}_{2}$ crystal onto the crystalline CNC was carried out at different sulfuric acid molar concentration (AMC) values from 0.03 up to $0.4 \mathrm{M}$ - which refer to $\mathrm{pH}$ values from 2 to 0.05 respectively.

Table 1 Experimental parameters varied during the synthesis of $\mathrm{CNC}-\mathrm{TiO}_{2}$ hybrid nanostructures

\begin{tabular}{|c|c|c|c|c|c|c|c|c|c|c|c|c|c|c|}
\hline $\begin{array}{l}\text { Sulfuric acid molar } \\
\text { concentration (AMC) }[\mathrm{M}]\end{array}$ & 0.003 & 0.005 & 0.01 & 0.02 & 0.03 & 0.05 & 0.07 & 0.1 & 0.15 & 0.18 & 0.25 & 0.3 & 0.35 & 0.4 \\
\hline Precursor concentration (PC) $\left[\mathrm{g} \mathrm{l}^{-1}\right]$ & 0.1 & & & & 0.3 & & & & 0.7 & & & 0.9 & & \\
\hline Reaction temperature $(\mathrm{RT})\left[{ }^{\circ} \mathrm{C}\right]$ & 40 & & & & & 70 & & & & & 90 & & & \\
\hline
\end{tabular}




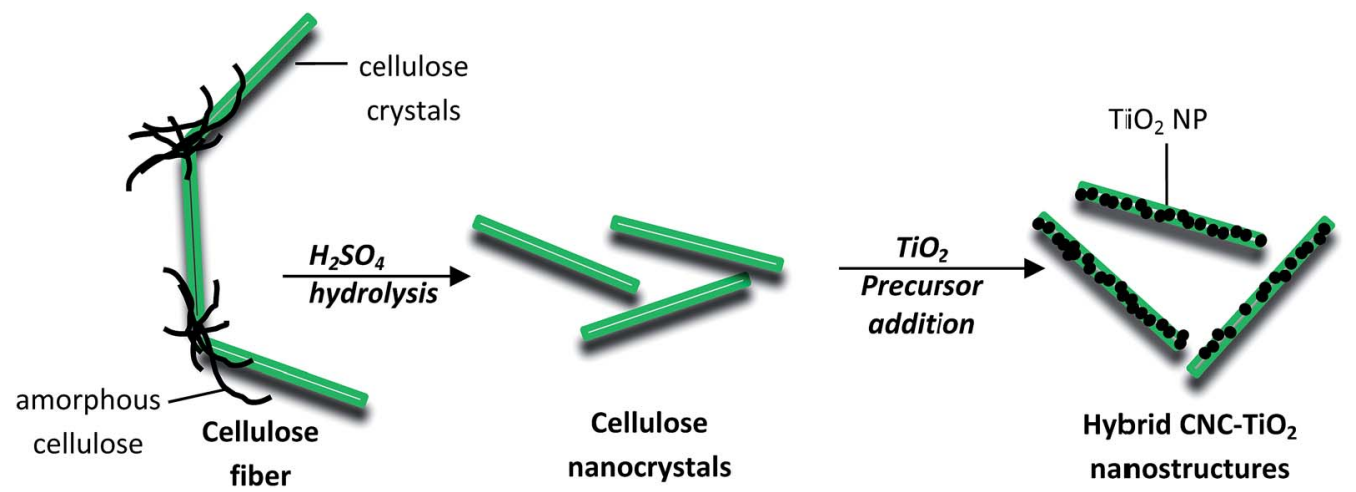

Fig. 1 Proposed schematic of a $\mathrm{CNC}-\mathrm{TiO}_{2}$ hybrid nanostructure preparation.

Varying concentration of sulfuric acid led to different crystallization processes. Fig. 2 summarizes the results obtained from XRD spectra as a function of the AMC in CNC suspension. The presence of CNC is clearly identified by specific peaks at $2 \theta=20$ and $22.5^{\circ}$ (ref. 50) whereas $\mathrm{TiO}_{2}$ might appear as two different allomorphs anatase and rutile at $25^{\circ}$ and $27^{\circ}$ respectively. ${ }^{51} \mathrm{As}$ shown in Fig. 2(a), an AMC $\leq 0.03 \mathrm{M}$ does not favor the crystallization of the $\mathrm{TiO}_{2} \mathrm{NP}$. At low acid concentration, apart from two CNC peaks at 20 and $22.5^{\circ}$, no peak specific to titanium is visible. The complete hydrolysis of the precursor i.e. $\mathrm{TiOSO}_{4}$, does not take place. As a result, if we consider that Ti is effectively present, the $\mathrm{Ti}^{4+}$ remains amorphous. The conditions for the anatase formation gradually become more favorable when the AMC is further increased $(0.03 \leq \mathrm{AMC} \leq 0.15 \mathrm{M})$. A clear peak at $2 \theta=25^{\circ}$ in the corresponding XRD spectrum confirms this (Fig. 2(b); $\mathrm{AMC}=0.13 \mathrm{M}$ ). By further increasing the AMC (AMC $\geq 0.15 \mathrm{M}$ ), the reaction conditions become favorable for rutile formation. As a result, the XRD spectrum (shown for AMC $=0.18 \mathrm{M}$ ) shows a clear peak at $2 \theta=27^{\circ}$ specific to the rutile crystalline form (Fig. 2(c)).

TEM was used to determine the distribution of $\mathrm{TiO}_{2} \mathrm{NP}$ along the hybrid $\mathrm{CNC}-\mathrm{TiO}_{2}$ nanostructures. Fig. 3(a) shows the
TEM image of the hybrid nanostructures which were prepared using a CNC suspension of $0.18 \mathrm{M} \mathrm{H}_{2} \mathrm{SO}_{4}$ with precursor concentration (PC) of $0.7 \mathrm{~g} \mathrm{l}^{-1}$ and reaction temperature (RT) at $90{ }^{\circ} \mathrm{C}$ for $8 \mathrm{~h}(t)$. Nanorod-like structures with lengths varying from $150 \mathrm{~nm}$ to $500 \mathrm{~nm}$ can be observed. Further magnification (Fig. 3(b)) shows very fine black points with sizes ranging from 2 to $6 \mathrm{~nm}$ which are distributed all over the length of CNC. A focus on these black points using HRTEM shows well defined crystalline structures with a fringe spacing of $0.33 \mathrm{~nm}$ (Fig. 3(c)), which represents the [110] plane with a distance specific to the rutile phase. ${ }^{52}$ No isolated $\mathrm{TiO}_{2} \mathrm{NP}$ were observed in any case, thus signifying the strength of adhesion between the two components, which remains intact even after sonication. If only $\mathrm{TiOSO}_{4}$ concentration was varied at $0.1,0.3,0.7$ and $0.9 \mathrm{~g} \mathrm{l}^{-1}$, keeping all other synthesis parameters constant (i.e. $\mathrm{AMC}=$ $0.18 \mathrm{M}, \mathrm{RT}=90^{\circ} \mathrm{C}, t=8 \mathrm{~h}$ ), a clear difference in the aggregation state of nucleated $\mathrm{TiO}_{2} \mathrm{NP}$ was observed as follows:

- Insufficient nucleation for the hybrid sample at $0.1 \mathrm{~g} \mathrm{l}^{-1}$ (Hyb0.1; Fig. 4(a))

- Dispersed and heterogeneous nucleation for the hybrid sample at $0.3 \mathrm{~g} \mathrm{l}^{-1}$ (Hyb0.3; Fig. 4(b))

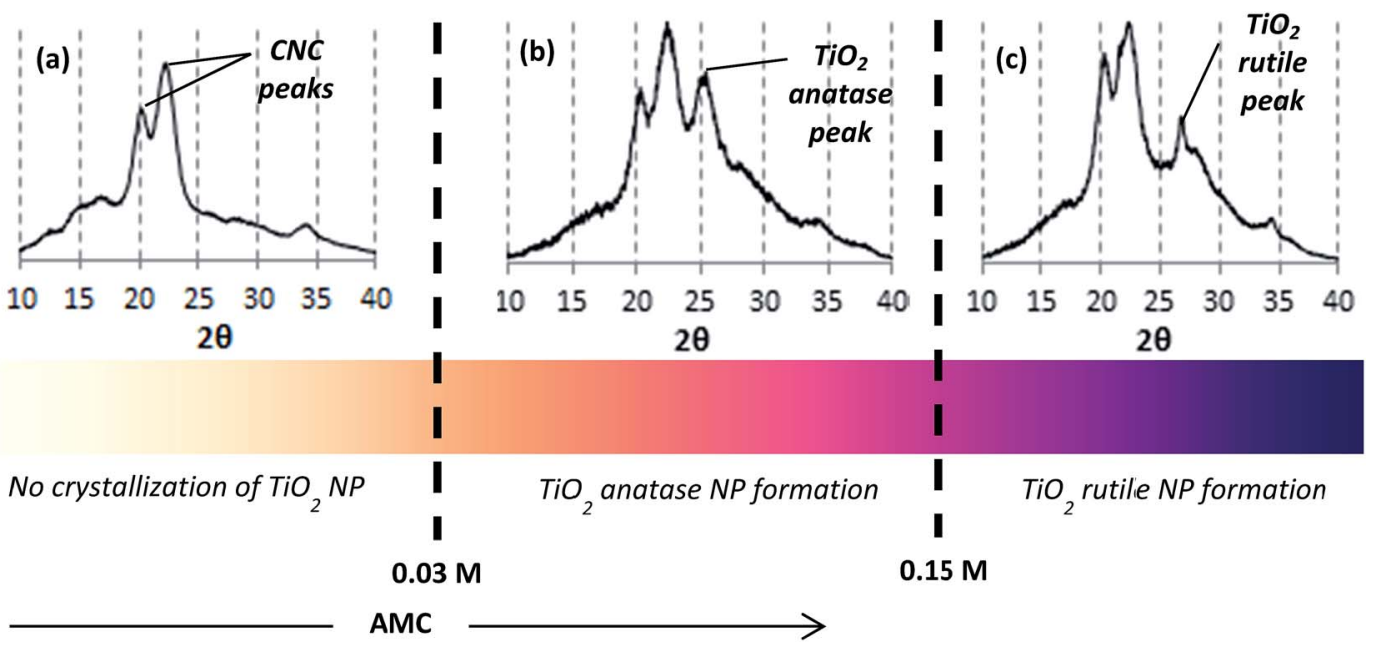

Fig. 2 Gradual variation of the crystalline phase of the $\mathrm{TiO}_{2} \mathrm{NP}$ with the increase in the CNC suspension AMC for (a) insufficiently acidic conditions ( $\mathrm{pH}>2$ ), AMC $<0.03 \mathrm{M}$; (b) mild acidic conditions, $0.03 \leq \mathrm{AMC} \leq 0.15 \mathrm{M}$; (c) highly acidic conditions, AMC > $0.15 \mathrm{M}$. 

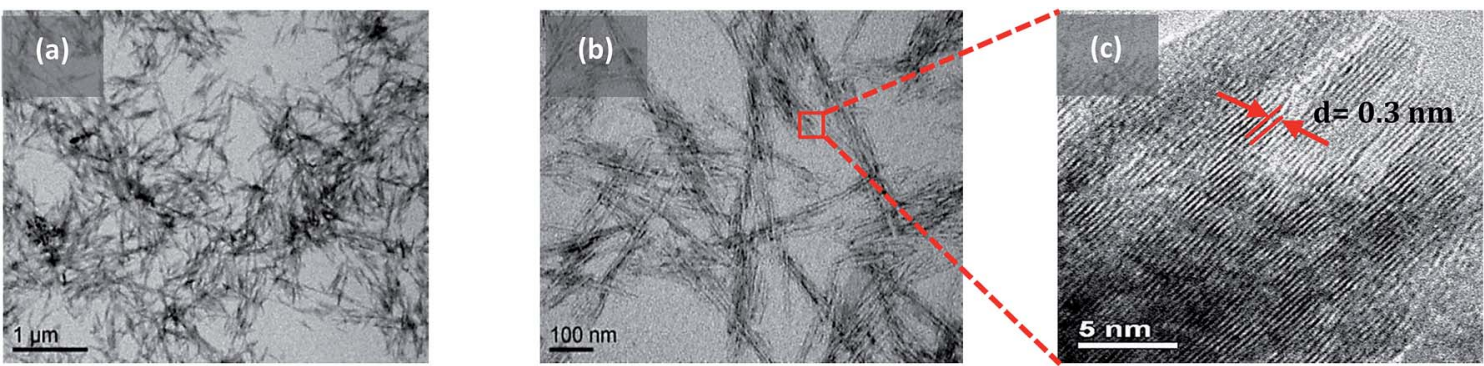

Fig. 3 (a and b) TEM images of the $\mathrm{CNC}-\mathrm{TiO}_{2}$ hybrid nanostructures at two magnifications. (c) HRTEM image of one of the nucleated TiO 2 NP showing the rutile crystal planes.

- Dispersed and homogeneous nucleation for the hybrid sample at $0.7 \mathrm{~g} \mathrm{l}^{-1}$ (Hyb0.7; Fig. 4(c))

- Aggregated and heterogeneous nucleation for the hybrid sample at $0.9 \mathrm{~g} \mathrm{l}^{-1}$ (Hyb0.9; Fig. 4(d))

Fig. 4(e) quantifies the average $\mathrm{TiO}_{2} \mathrm{NP}$ crystal sizes obtained from XRD spectra using the Scherrer equation for Hyb0.3, Hyb0.7 and Hyb0.9 using the peak at $2 \theta=27^{\circ}$ specific to the rutile crystalline form. Since not enough $\mathrm{TiO}_{2}$ crystals were detected in Hyb0.1, it is excluded from the quantification analysis. An increasing NP mean size (from 4.2 to $7.2 \mathrm{~nm}$ ) with the increasing PC can be observed. This NP size range is very low compared with 20-30 nm for the $\mathrm{TiO}_{2} \mathrm{NP}$ generally found in commercial products. Also, a broader size distribution for Hyb0.3 and Hyb0.9 is observed which can be attributed to the heterogeneity in $\mathrm{TiO}_{2} \mathrm{NP}$ sizes as compared with Hyb0.7, which has homogeneous $\mathrm{TiO}_{2}$ NP sizes and hence narrower size distribution. These results are in accordance with the microscopic observations shown in Fig. 4(b-d).

When analyzed thermogravimetrically, except for Hyb0.1, no considerable difference in the $\mathrm{TiO}_{2}$ content was observed (in mass content; Fig. 5) for Hyb0.3, Hyb0.7 and Hyb0.9. The major peak in the $\mathrm{d} M \mathrm{~d} T^{-1}$ curve (mass\% derivative w.r.t. temperature) occurs at $140{ }^{\circ} \mathrm{C}$, which corresponds to the volatile and aqueous content loss and is equal to $27 \%$ of total hybrid sample mass. The CNC gets completely eliminated at $670{ }^{\circ} \mathrm{C}$. Therefore, beyond this temperature, the remaining mass $\%$ corresponds to the $\mathrm{TiO}_{2}$ content. Eliminating water content, $\mathrm{TiO}_{2}$ mass\% is equal to $33 \%$ for the three hybrids. Hence, CNC accounts for

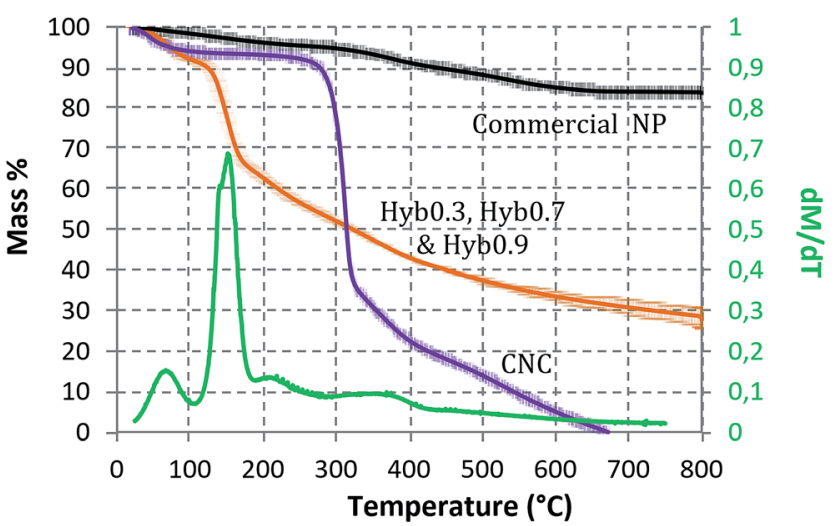

Fig. 5 Temperature-induced oxidation curves of Eusolex® TS NP (commercial grade NP), $\mathrm{CNC}-\mathrm{TiO}_{2}$ hybrid nanostructures and $\mathrm{CNC}$ (as reference); the variation of the derived mass\% w.r.t. temperature is shown in green.
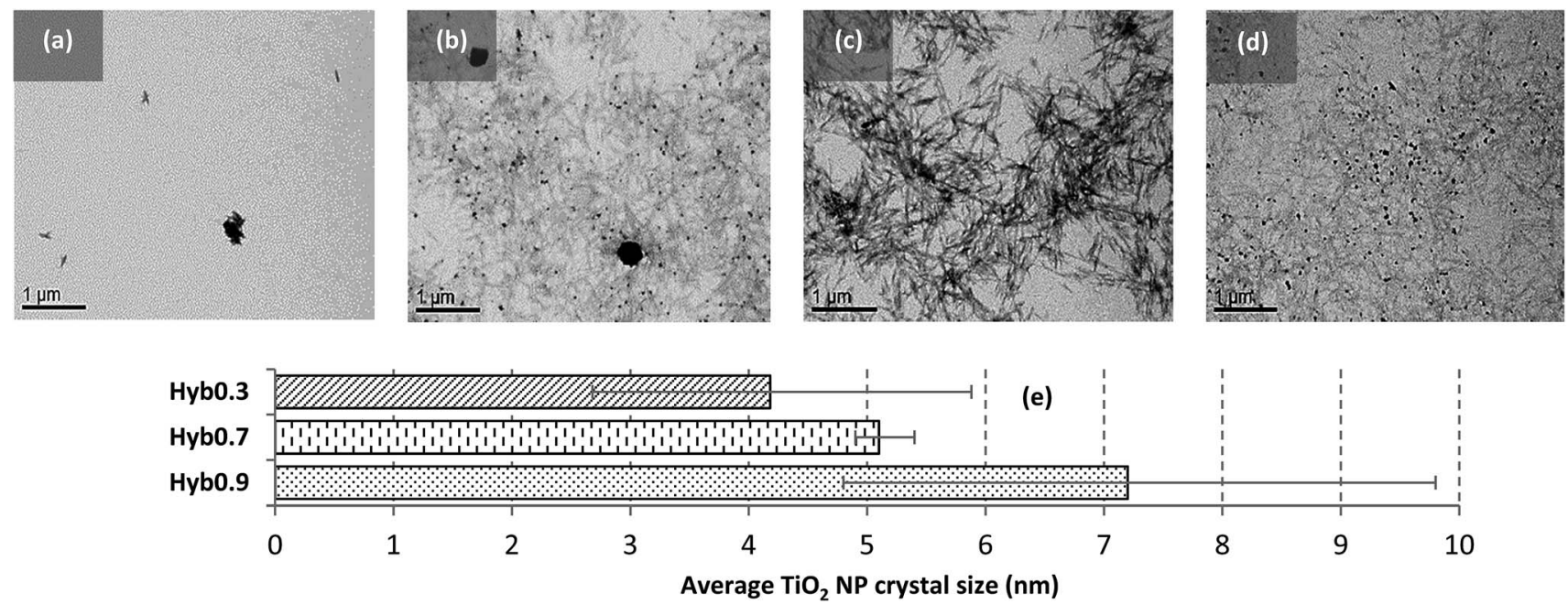

Fig. 4 TEM images of (a) Hyb0.1, (b) Hyb0.3, (c) Hyb0.7 and (d) Hyb0.9. (e) Size comparison of nucleated TiO $\mathrm{NP}$ crystals in different hybrid samples. (Scale bars: $1 \mu \mathrm{m}$.) 
$67 \%$ of the total hybrid sample mass for these three samples. In the case of Hyb0.1, the $\mathrm{TiO}_{2}$ content is equal to $20 \%$. Under the same conditions, a commercial grade of $\mathrm{TiO}_{2} \mathrm{NP}$ (Eusolex® $\mathrm{TS}$; Merck) was found to have $83 \%$ of the total mass as $\mathrm{TiO}_{2}$, i.e. approximately 3 times the $\mathrm{TiO}_{2}$ content in hybrid samples. Eusolex® TS is one of the most commonly used UV filters in commercial skin care products. It is composed of $\mathrm{TiO}_{2} \mathrm{NP}$ in rutile form coated with alumina and stearic acid.

The average NP size is $\sim 20 \mathrm{~nm} .{ }^{53,54}$ For the considered RT (i.e. 40,70 and $90{ }^{\circ} \mathrm{C}$ ) and $t(3,5$ and $8 \mathrm{~h}$ ) values, no specific effect on the size and crystallinity of $\mathrm{TiO}_{2} \mathrm{NP}$ was observed. However, these two parameters are being dealt with in detail in our ongoing study by enlarging their ranges.

\section{UV absorbance}

Hyb0.1, Hyb0.3, Hyb0.7 and Hyb0.9 were also analyzed for their capacity to absorb UV rays with respect to Eusolex ${ }^{\circledR}$ TS, the commercial product already used in sunscreens. The absorbance of each sample is shown in Fig. 6(a) for the entire spectrum of UVA and UVB regions. The $\mathrm{TiO}_{2}$ mass concentration in each sample is $0.046 \mathrm{~g} \mathrm{l}^{-1}$ (refer to $\mathrm{ESI}_{\dagger} \dagger$ for calculation details). For the same $\mathrm{TiO}_{2}$ mass concentration, the size and degree of dispersion of the nucleated $\mathrm{TiO}_{2}$ NP have direct effects on their UV absorption capacities. For Hyb0.7, the sample with most dispersed and homogeneously nucleated $\mathrm{TiO}_{2} \mathrm{NP}$, the UV absorption is maximal, even more than the commercial NP. While the equivalent concentration of CNC does not show any UV absorption activity, it is minimal for Hyb0.1 - the sample with most aggregated and insufficiently nucleated $\mathrm{TiO}_{2} \mathrm{NP}$. For comparison, in Fig. 6(b), the UV absorbance calibration curve at $300 \mathrm{~nm}$ wavelength of the commercial NP is shown. The UV absorbance of Hyb0.7 at the same $\mathrm{TiO}_{2}$ mass concentration is 2.25. This sample corresponds on the calibration curve to an equivalent $\mathrm{TiO}_{2}$ mass concentration of $0.064 \mathrm{~g} \mathrm{l}^{-1}$. This means that the UV absorbance of Hyb0.7 is 1.4 times more efficient than that of the commercial NP at $\lambda=300 \mathrm{~nm}$. Fig. 6(c) illustrates this comparison for the four hybrid samples. Owing to lesser homogeneity and higher aggregation of nucleated $\mathrm{TiO}_{2}$ NP, Hyb0.1, Hyb0.3 and Hyb0.9 have lower UV absorbance than the commercial grade material. In Fig. 6(d), the improvement factor (IF) is plotted as a function of Hyb0.7 concentration in an aqueous suspension. The maximum improvement reaches towards $1.5 \mathrm{~g} \mathrm{l}^{-1}$ and stabilizes, thus revealing twice the efficiency. This means that the ratio of the amount of Hyb0.7 to UV absorbance can be improved (with respect to commercial $\mathrm{TiO}_{2}$ $\mathrm{NP}$ ) only up to a certain limit. It should be noted that the absorbance spectra of the tested nanomaterials (hybrid, commercial and $\mathrm{CNC}$ ) were observed to remain unaltered even after a 2 hour exposure to UV rays. This type of behavior demonstrates their photostability against UV rays (refer to the ESI $\dagger$ ).

\section{Pickering emulsion interface stability}

CNC are already recognized to be adsorbed efficiently at the interface to stabilize oil-in-water emulsions, thus replacing integrally the use of surfactants in formulations. Similarly,
Hyb0.7 was tested for its ability to stabilize emulsions. Mixtures containing hexadecane and aqueous suspensions of Hyb0.7, in a ratio $20 / 80$, were produced, showing excellent stability for several weeks. Fig. 7 shows a clear reduction in the average oil droplet size with the increasing Hyb0.7 concentration in the emulsion. Beyond a certain point, the droplet size reduction stops, even with further sonication. Better defined by the inverse diameter (see inset in Fig. 7), this point occurs at $0.48 \mathrm{~g}$ $\mathrm{1}^{-1}$ of Hyb0.7 (point A) and reveals the change in coverage mode of the droplets. As already described for the pristine $\mathrm{CNC},{ }^{35,39}$ the nanomaterial irreversibly adsorbs at the interface, forming a monolayer on the surface of oil droplets. Whatever the nanomaterial concentration, stable emulsions are obtained that can be kept over months. At low concentrations, a clear decrease of the drop diameter is observed in the so-called limited coalescence domain, ${ }^{55}$ i.e. above $0.48 \mathrm{~g} \mathrm{l}^{-1}$. The drop size is then controlled by the nanomaterial concentration. Beyond the coalescence domain, the drop size is stabilized. As shown in Fig. 7 , the rod-like nature of such nanomaterials allows their reorganization at the interface, leading to densification of this monolayer with higher surface coverage of the oil-water interface, which ultimately leads to a local orientation/alignment of these nanomaterials, providing higher surface density and resistance to the emulsion.

Fig. 8 shows images of the oil droplets observed using an optical microscope, evidencing the drastic reduction in the oil droplet size with increasing Hyb0.7 concentration. However, this reduction is not apparent in Fig. 8(d), which indicates droplet size saturation. The emulsion volume (see the insets) is increased as well as resistance to shear at the higher concentrations. These experiments were carried out with hexadecane to compare the ability to stabilize emulsions with systems already studied. Similar results were obtained using two of the most commonly employed oils in cosmetic products: cococaprylate and isopropyl palmitate (refer to the ESI $\dagger$ ). This confirms the fact that Hyb0.7 is capable of stabilizing emulsions prepared using a range of oils.

\section{CNC- $\mathrm{TiO}_{2}$ association}

Quantification of surface modification on NP, in general, is a challenging issue since the surface in itself represents a low percentage of the total CNC. Using a bulk technique to quantify a surface phenomenon is then inherently problematic and surface scanning techniques at these nanoscales are hardly available. To determine favorable $\mathrm{TiO}_{2}$ nucleation sites on CNC, FTIR analysis was done. In Fig. 9, FTIR spectra of pure and Hyb0.7 CNC are compared. Even if non-quantitative, such an approach is able to indicate surface group variation. It can be clearly observed that the IR spectrum of Hyb0.7 is completely dominated by that of pure CNC except at 1720, 580 and 460 $\mathrm{cm}^{-1}$, where peak variations have appeared following the treatment with $\mathrm{Ti}$ precursor. The peak at $1720 \mathrm{~cm}^{-1}$ corresponds to the esterification of out-of-plane hydroxyl groups located on C6 of the glucose molecule (see inset to Fig. 9, showing a glucose molecule with numbered $\mathrm{C}$ atoms) i.e. $-\mathrm{CH}_{2} \mathrm{OH} \rightarrow-\mathrm{COOR}^{.56}$ A peak in the region $1600-1700 \mathrm{~cm}^{-1}$ is 

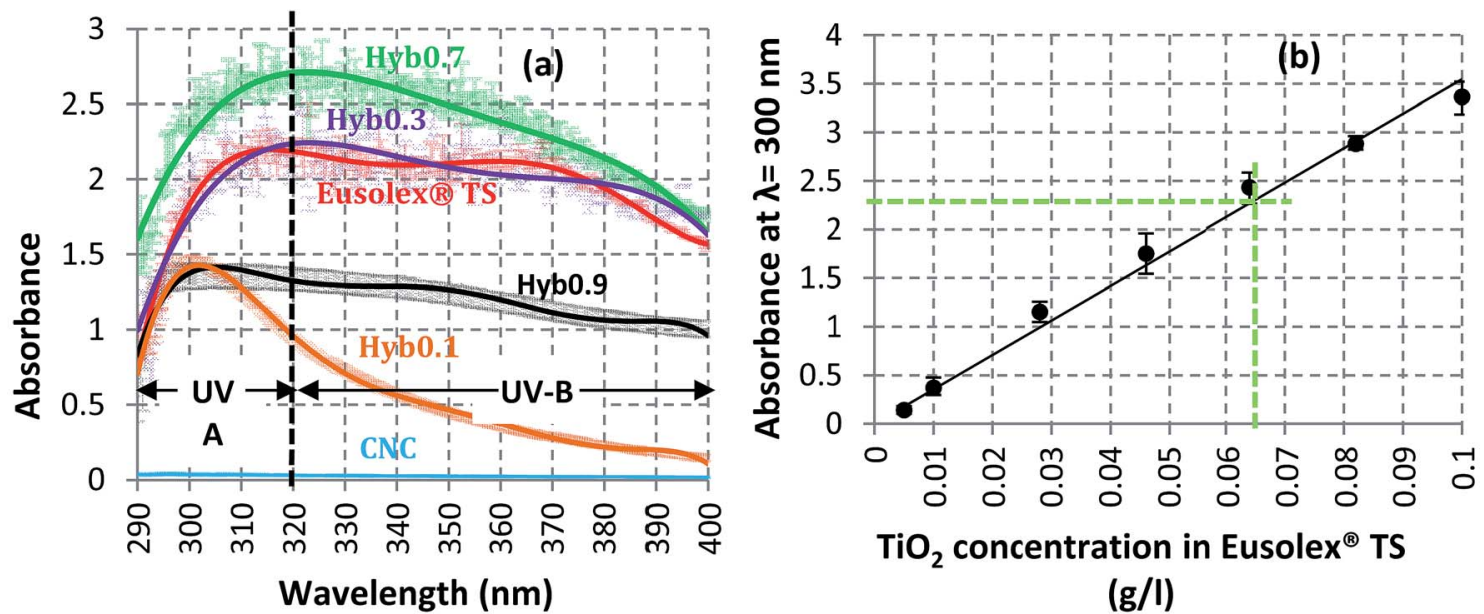

$\mathrm{TiO}_{2}$ concentration in Eusolex ${ }^{\circledR} \mathrm{TS}$

$(\mathrm{g} / \mathrm{l})$
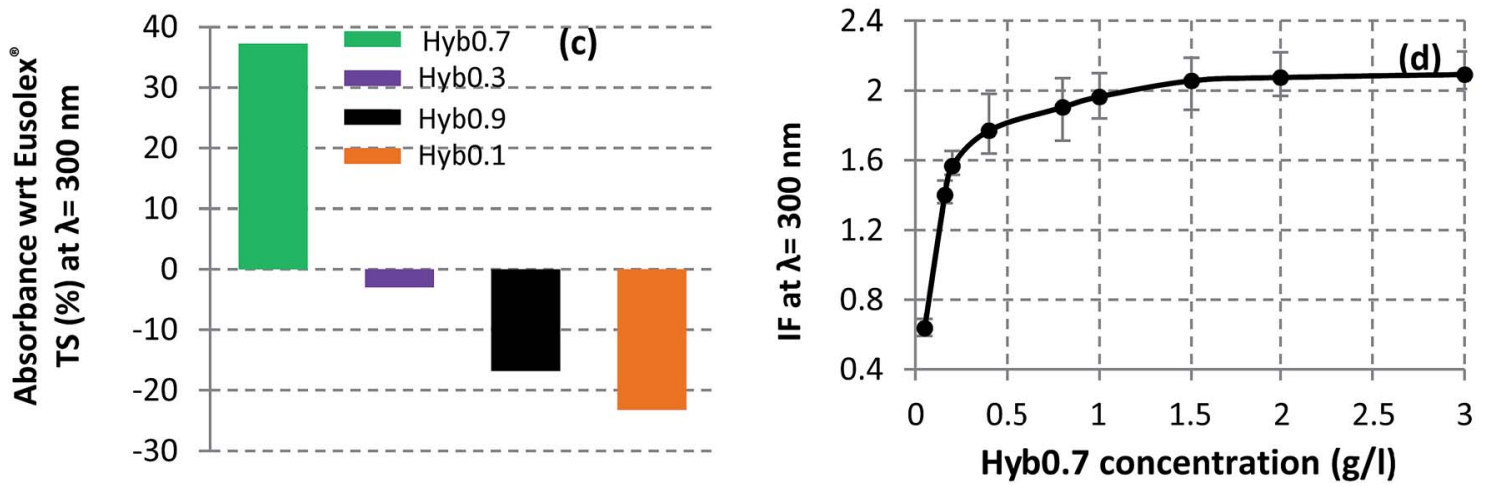

Fig. 6 (a) UV absorbance spectra for the hybrid samples and their comparison with the commercial grade NP over the entire UVA and UVB spectrum. (b) and (c) Quantification of the difference between the absorbance levels of the commercial grade NP and hybrid samples. (d) Improvement factor (IF) as a function of Hyb0.7 concentration in an aqueous suspension.

indicative of the presence of interstitial or adsorbed water. The complex absorption peak in the range $900-1250 \mathrm{~cm}^{-1}$ is mainly associated with stretching mode of $\mathrm{C}-\mathrm{O}-\mathrm{C}, \mathrm{C}-\mathrm{C}$ and $\mathrm{C}-\mathrm{O}$ groups. The peak at $710 \mathrm{~cm}^{-1}$, which corresponds to the out-of- plane hydroxyl group bending at $\mathrm{C} 6$ of the glucose molecule ${ }^{57}$ disappears when $\mathrm{CNC}$ is grafted with $\mathrm{TiO}_{2}$. This is a direct result of esterification of the $\mathrm{C6}$, which replaces the out-of-plane hydroxyl group with Ti. The peak centered at $580 \mathrm{~cm}^{-1}$ is

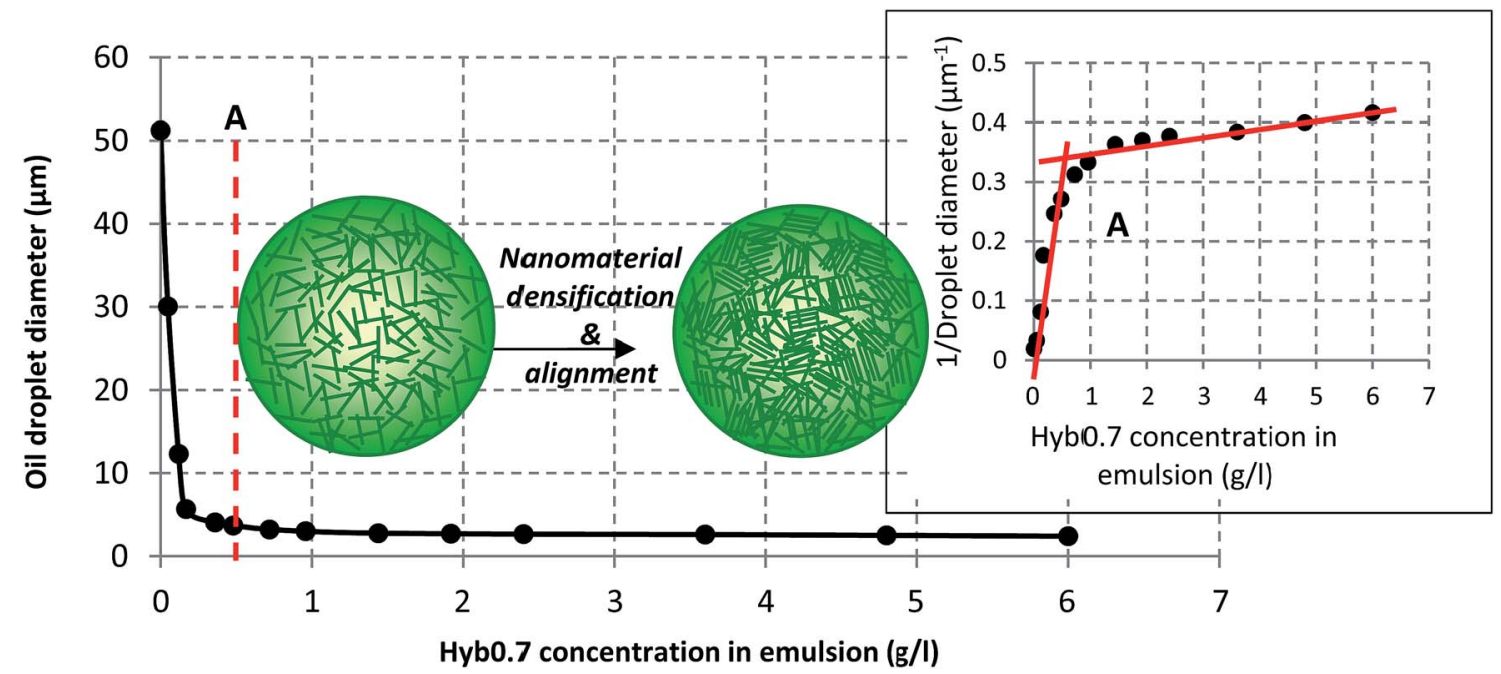

Fig. 7 Variation of the oil droplet size with increasing Hyb0.7 concentration; the figure inset shows the way to determine the droplets' coalescence limit (point A). 


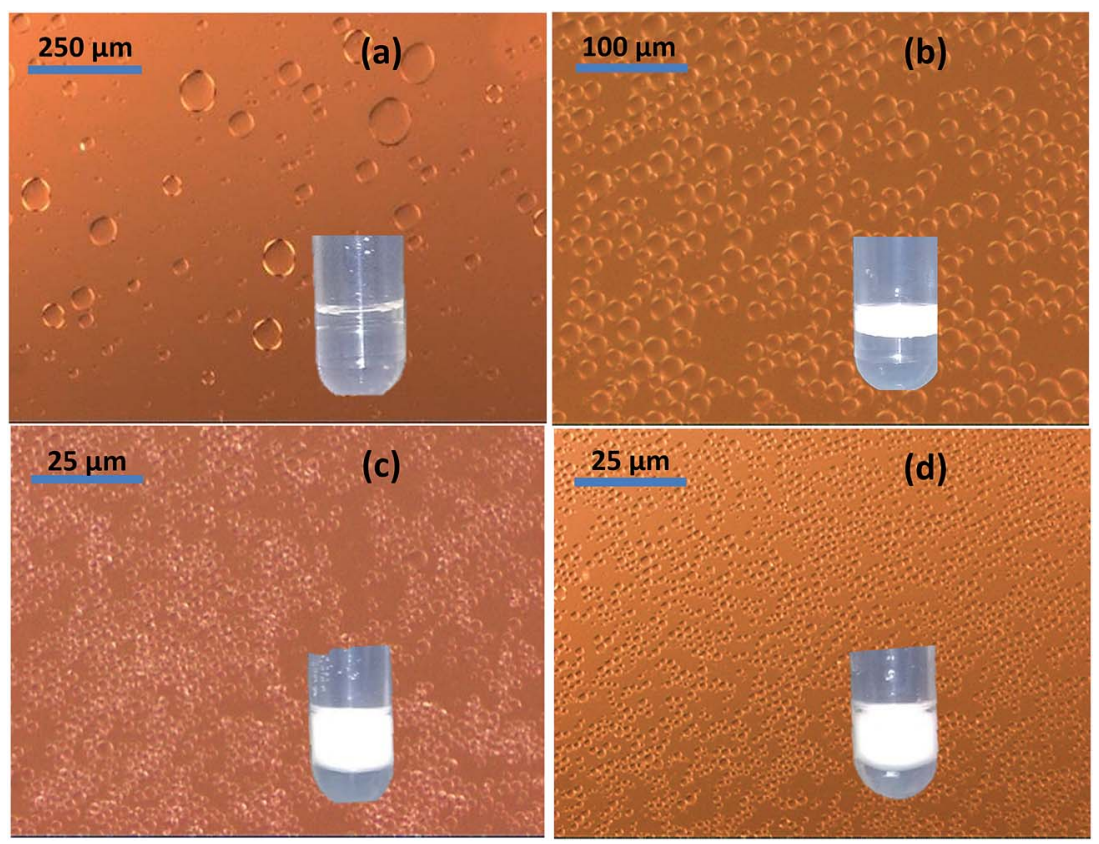

Fig. 8 Variation of the oil droplet size for (a) 0.05 , (b) 0.17 , (c) 1.44 and (d) $3.6 \mathrm{~g} \mathrm{l}^{-1}$ of Hyb0.7 in emulsion. Please note the change in scale for the first three images.

likely due to the vibration of $\mathrm{Ti}-\mathrm{O}$ bonds in the $\mathrm{TiO}_{2}$ lattice. ${ }^{58} \mathrm{~A}$ rutile band is present at $460 \mathrm{~cm}^{-1} .{ }^{59}$ Based on IR spectra observations, one may propose that $\mathrm{C} 6$ of the glucose molecule is the favorable $\mathrm{TiO}_{2}$ nucleation site where intermediate titanium hydroxide (yielded during acid hydrolysis of the precursor) interacts with out-of-plane hydroxyl group via hydrogen bonding and thus replaces the out-of-plane hydroxyl group.

The continuous heating reaction, in the presence of $\mathrm{Ti}^{4+}$ ion, may induce the oxidation and hence esterification of $\mathrm{C} 6$, as suggested by FTIR in Fig. 9. This may further initiate $\mathrm{TiO}_{2}$ crystal nucleation. As the reaction proceeds, the $\mathrm{TiO}_{2} \mathrm{NP}$ crystal growth is confined along the [110] direction (suggested by XRD observation in Fig. 2(c)). This is envisageable because the out-of- plane hydroxyl groups are equatorial to the CNC ring plane and the hydrogen bonding is most prevalent within the [110] plane. There are characterization tests ongoing to confirm this association hypothesis.

\section{Discussion}

We have observed the primary dependence of $\mathrm{TiO}_{2}$ polymorph type on the acidic conditions of the CNC suspension. For the sake of comparison, $\mathrm{AMC}=0.003$ is equivalent to $\mathrm{pH}=2$; $\mathrm{AMC}$ $=0.18$ is equivalent to $\mathrm{pH}=0.4$ and $\mathrm{AMC}=0.4$ is equivalent to $\mathrm{pH}=0.05$. Simply by varying the suspension AMC, the reaction conditions gradually become favorable for $\mathrm{TiO}_{2}$ in either amorphous or anatase or rutile crystal polymorph. Hence, no

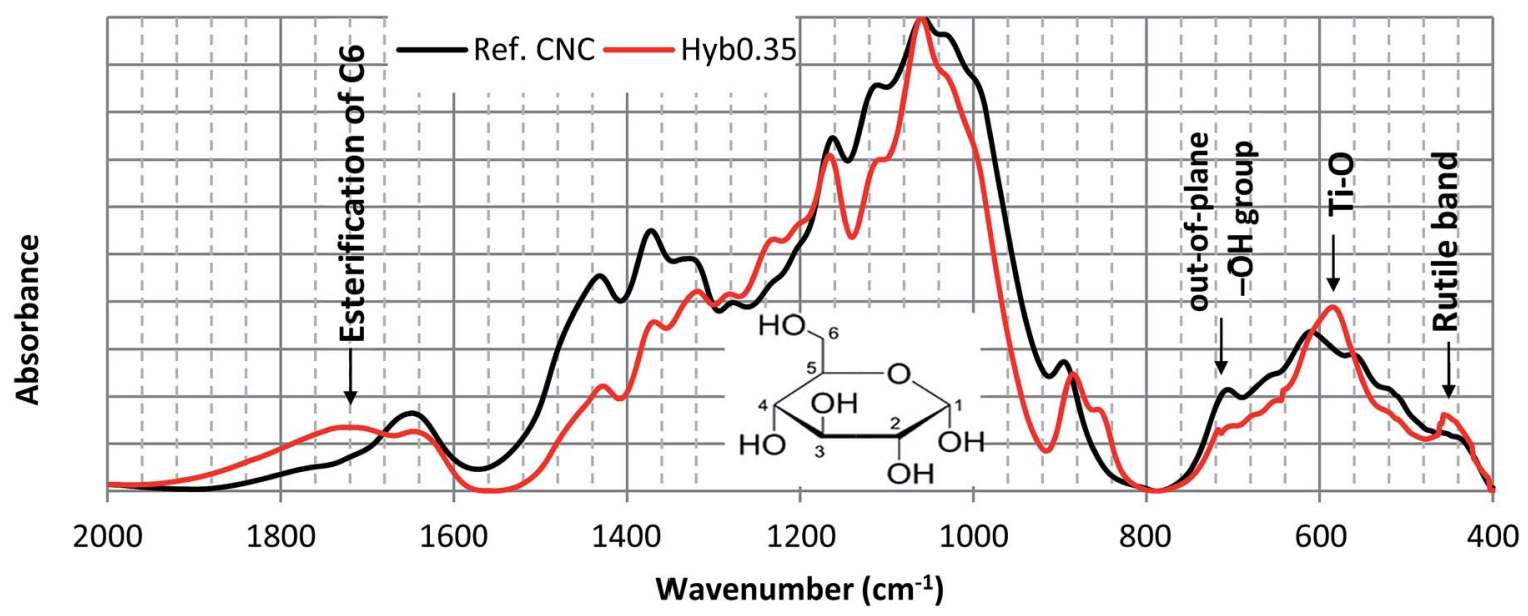

Fig. 9 FTIR spectra of Hyb0.7 and reference CNC. 
conventional high temperature thermal treatments were required to obtain the two polymorphs during the synthesis process as seen frequently for coarse crystals. A similar observation was made by Penn and Banfield ${ }^{\mathbf{6 0}}$ for crystal transformation between anatase and brookite (another lesser known polymorph of $\mathrm{TiO}_{2}$ ). They reported that much lower temperature is required to accomplish atomic displacements for the synthesis of nanocrystals than that required in millimeter-sized coarser materials. Another similar study ${ }^{\mathbf{6 1}}$ explains how aqueous titanium species that occur in acid media change with AMC or $\mathrm{pH}$. For example, for $\mathrm{pH}<1, \mathrm{Ti}^{4+}$ ions are more likely to be formed. For less acidic solutions $(\mathrm{pH}>1)$, formation of $\mathrm{TiO}^{2+}$ ions is more prevalent. They also suggested that with high sulfate ion concentration (contributed by both acid and precursor in the present case), species such as $\left[\mathrm{TiO}\left(\mathrm{SO}_{4}\right)_{2}\right]^{2-}$ and $\left[\mathrm{TiO}\left(\mathrm{SO}_{4}\right)_{4}\right]^{4-}$ may also form. Wu et al. ${ }^{62}$ proposed $\mathrm{TiO}_{2}$ particle formation resulting from the hydrolysis of $\mathrm{Ti}^{4+}$ ion as follows:

$$
\begin{gathered}
m \mathrm{TiOSO}_{4}+m \mathrm{H}_{2} \mathrm{SO}_{4} \rightarrow m \mathrm{Ti}(\mathrm{OH})_{4}+3 m \mathrm{H}_{2} \mathrm{O} \\
m \mathrm{Ti}(\mathrm{OH})_{4} \rightarrow m \mathrm{TiO}_{2}+2 m \mathrm{H}_{2} \mathrm{O}
\end{gathered}
$$

However, in order to conclude the reason for $\mathrm{TiO}_{2}$ polymorph type dependence on acidity, further studies are required which should consider the role of sulfate ions present on CNC too, apart from the aqueous chemistry of titanium.

The titanium precursor concentration seemed to control the size and distribution of the nucleated $\mathrm{TiO}_{2}$ NP crystals. The average $\mathrm{TiO}_{2} \mathrm{NP}$ crystal size was observed to vary from 4 to $7.2 \mathrm{~nm}$, depending on the precursor concentration value. A well dispersed and homogeneous nucleation of $\mathrm{TiO}_{2} \mathrm{NP}$ was observed for $\mathrm{PC}=0.7 \mathrm{~g} \mathrm{l}^{-1}$ i.e. Hyb0.7. For lower or higher PC values, various degrees of dispersion and heterogeneity were observed. The UV absorbance was observed to be completely proportional to the dispersion homogenization and high surface area of the nucleated $\mathrm{TiO}_{2} \mathrm{NP}$. These two parameters are, in turn, proportional to the number of available crystal nucleation sites i.e. out-of-plane hydroxyl groups present on C6 of CNC. Once these sites are saturated or are inaccessible, $\mathrm{Ti}^{4+}$ ions will interact with the already adsorbed $\mathrm{Ti}^{4+}$ ions and contribute towards crystal growth. Hence, for a given quantity of CNC, there must be a critical PC value beyond which crystal growth is more favorable than crystal nucleation. This controls both crystal size and distribution. Under the present experimental conditions, we assume this critical PC value to be equal to $0.7 \mathrm{~g} \mathrm{l}^{-1}$. Larger and less efficient structures of $\mathrm{TiO}_{2} \mathrm{NP}$ are observed in the case of Hyb0.9.

\section{Conclusions}

The present study develops a way to chemically synthesize hybrid nanostructures where native cellulose nanocrystals are used as template, with controlled $\mathrm{TiO}_{2}$ crystal size, allomorph, and distribution along the CNC. These hybrid nanoparticles appear effective as an alternative to the use of conventional rutile $\mathrm{TiO}_{2}$ NP during skin care product formulation. Thanks to a homogeneous distribution and high surface area of in situ
$\mathrm{TiO}_{2}$ NP grafting on CNC, the overall capacity of UV absorbance improves as compared with the conventional counterparts. For Hyb0.7, which showed the most homogeneous and well dispersed $\mathrm{TiO}_{2} \mathrm{NP}$ nucleation among the hybrid samples, the UV absorbance is 1.4 times higher at $\lambda=300 \mathrm{~nm}$. For the presently chosen PC range, no considerable effect on generated $\mathrm{TiO}_{2}$ mass $\%$ was detected as it was 33\% for all hybrid samples (except for Hyb0.1, which showed insufficient nucleation). Furthermore, our hybrid nanoparticles proved to be able to replace surfactants in formulation, forming a highly stable oilin-water Pickering emulsion.

Sustainability of the hybrid nanostructures developed in the present study should now be studied to assess their complete environmental impact. These studies should include various in vitro and in vivo tests to evaluate inflammatory responses during toxicological and eco-toxicological studies, exposure assessment during end-of-life stage, etc.

\section{Acknowledgements}

This work was carried out in the framework of the Labex SERENADE (ANR-11-LABX-0064) and the A*MIDEX Project (ANR-11-IDEX-0001-02), funded by the French Government program Investissements d'Avenir, and managed by the French National Research Agency (ANR). We are equally grateful to Emilie Perrin, Joëlle Davy, Bruno Pontoire, Emmanuelle Morin Picardat and Sylvie Durand (INRA) as well as to Nicolas Stephant and Nicolas Gautier (Institut des Matériaux Jean Rouxel, Université de Nantes) for their excellent technical assistance and experimental results analysis.

\section{References}

1 H. Lin, C. P. Huang, W. Li, C. Ni, S. I. Shah and Y. H. Tseng, Appl. Catal., B, 2006, 68, 1-11.

2 C. Antoniou, M. G. Kosmadaki, A. J. Stratigos and A. D. Katsambas, J. Eur. Acad. Dermatol. Venereol., 2008, 22, 1110-1118.

3 S. Seite, A. Colige, P. P. Vivenot, C. Montastier, A. A. Fourtanier, C. Lapière and B. Nusgens, Photodermatol., Photoimmunol. Photomed., 2000, 16, 147-155.

4 S. K. Wang, I. Balagula and U. Osterwalder, Dermatology and Therapy, 2010, 23, 31-47.

5 T. G. Smijs and S. Pavel, Nanotechnol., Sci. Appl., 2011, 4, 95112.

6 I. Fenoglio, J. Ponti, E. Alloa, M. Ghiazza, I. Corazzari, R. Capomaccio, D. Rembges, S. Oliaro-Bossoc and F. Rossi, Nanoscale, 2013, 5, 6567-6576.

7 J. Wu, W. Liu, C. Xue, S. Zhou, F. Lan, L. Bi, H. Xu, X. Yang and F. D. Zeng, Toxicol. Lett., 2009, 191, 1-8.

8 A. V. Zvyagin, X. Zhao, A. Gierden, W. Sanchez, J. A. Ross and M. S. Roberts, J. Biomed. Opt., 2008, 13, 064031.

9 Á. Z. Kiss, T. Bíró, G. Czifra, I. Juhász, Z. S. Kertész, B. Kiss, Z. Szikszai, B. I. Tóth and J. Hunyadi, NANODERM: Quality of skin as a barrier to ultra-fine particles, http:// w3.atomki.hu/ar2007/7_biol/kissaz.pdf, accessed December 2016. 
10 A. D. Maynard, Nature, 2006, 444, 267-269.

11 N. Shandilya, M. Morgeneyer and O. Le Bihan, J. Aerosol Sci., 2015, 89, 43-57.

12 N. Shandilya, M. Morgeneyer and O. Le Bihan, J. Aerosol Sci., 2015, 89, 1-17.

13 L. Yan, F. Zhao, S. Li, Z. Hu and Y. Zhao, Nanoscale, 2011, 3, 362-382.

14 G. A. Sotiriou, C. Watson, K. M. Murdaugh, T. H. Darrah, G. Pyrgiotakis, A. Elder, J. D. Brain and P. Demokritou, Environ. Sci.: Nano, 2014, 1, 144-153.

15 R. Damoiseaux, S. George, M. Li, S. Pokhrel, Z. Ji, B. France, T. Xia, E. Suarez, R. Rallo, L. Madler, Y. Cohen, E. M. V. Hoek and A. Nel, Nanoscale, 2011, 3, 1345-1360.

16 P. Demokritou, S. Gass, G. Pyrgiotakis, J. M. Cohen, W. Goldsmith, W. McKinney, D. Frazer, J. Ma, D. SchweglerBerry, J. Brain and V. Castranova, Nanotoxicology, 2013, 7, 1338-1350.

17 D. Movia, V. Gerard, C. M. Maguire, N. Jain, A. P. Bell, V. Nicolosi, T. O'Neill, D. Scholz, Y. Gun'ko, Y. Volkov and A. Prina-Mello, Biomaterials, 2014, 35, 2543-2557.

18 N. Shandilya, O. Le Bihan, C. Bressot and M. Morgeneyer, Environ. Sci. Technol., 2015, 49, 2163-2170.

19 M. Morgeneyer, N. Shandilya, Y. M. Chen and O. Le Bihan, Chem. Eng. Res. Des., 2015, 93, 251-256.

20 N. Shandilya, O. Le Bihan and M. Morgeneyer, J. Nanomater., 2014, 289108.

21 R. J. Moon, A. Martini, J. Nairn, J. Simonsen and J. Youngblood, Chem. Soc. Rev., 2011, 40, 3941-3994.

22 D. Klemm, F. Kramer, S. Moritz, T. Lindstrom, M. Ankerfors, D. Gray and A. Dorris, Angew. Chem., Int. Ed., 2011, 50, 54385466.

23 S. Eyley and W. Thielemans, Nanoscale, 2014, 6, 7764-7779.

24 J. George and S. N. Sabapathi, Nanotechnol., Sci. Appl., 2015, $8,45-54$.

25 A. Dufresne, Mater. Today, 2013, 16, 220-227.

26 B. J. Harper, A. Clendaniel, F. Sinche, D. Way, M. Hughes, J. Schardt, J. Simonsen, A. B. Stefaniak and S. L. Harper, Cellulose, 2016, 23, 1763-1775.

27 J. B. Mougel, C. Adda, P. Bertoncini, I. Capron, B. Cathala and O. Chauvet, J. Phys. Chem. C, 2016, 120, 22694-22701.

28 K. R. Colacino, C. B. Arena, S. Dong, M. Roman, R. V. Davalos and Y. W. Lee, Technol. Cancer Res. Treat., 2015, 14, 757-766.

29 M. Roman, Ind. Biotechnol., 2015, 11, 25-33.

30 C. Endes, O. Schmid, C. Kinnear, S. Mueller, S. CamareroEspinosa, D. Vanhecke, E. J. Foster, A. Petri-Fink, B. R. Rutishauser, C. Weder and M. J. D. Clift, Part. Fibre Toxicol., 2014, 11, 1-12.

31 H. Ni, S. Zeng, J. Wu, X. Cheng, T. Luo, W. Wang, W. Zeng and Y. Chen, Bio-Med. Mater. Eng., 2012, 22, 121-127.

32 Z. Hanif, F. R. Ahmed, S. W. Shin, Y. K. Kim and S. H. Um, Colloids Surf., B, 2014, 119, 162-165.

33 Z. Hosseinidoust, M. N. Alam, G. Sim, N. Tufenkji and T. G. M. van de Ven, Nanoscale, 2015, 7, 16647-16657.

34 L. Du, K. Arnholt, S. Ripp, G. Sayler, S. Wang, C. Liang, J. Wang and J. Zhuang, Ecotoxicology, 2015, 24, 20492053.
35 N. Yanamala, M. T. Farcas, M. K. Hatfield, E. R. Kisin, V. E. Kagan, C. L. Geraci and A. A. Shvedova, ACS Sustainable Chem. Eng., 2014, 2, 1691-1698.

36 I. Kalashnikova, H. Bizot, B. Cathala and I. Capron, Langmuir, 2011, 27, 7471-7479.

37 C. T. Jackson, M. Paye and H. I. Maibach, in Handbook of Cosmetic Science and Technology, ed. A. O. Barel, M. Paye and H. I. Maibach, CRC Press, Boca Raton Florida, 4th edn, 2014 , ch. Mechanism of Skin Irritation by Surfactants and Anti-Irritants for Surfactant-based products, pp. 353-365.

38 B. P. Binks, Curr. Opin. Colloid Interface Sci., 2002, 7, 21-41. 39 V. Schmitt, M. Destribats and R. Backov, C. R. Phys., 2014, 15, 761-774.

40 F. Cherhal, F. Cousin and I. Capron, Biomacromolecules, 2016, 17, 496-502.

41 A. Jaroenworaluck, N. Pijarn, N. Kosachan and R. Stevens, Chem. Eng. J., 2012, 181, 45-55.

42 A. G. Cunha, J. B. Mougel, B. Cathala, L. A. Berglund and I. Capron, Langmuir, 2014, 30, 9327-9335.

43 K. R. Peddireddy, T. Nicolai, L. Benyahia and I. Capron, ACS Macro Lett., 2016, 5, 283-286.

44 P. A. A. P. Marques, T. Trindade and C. P. Neto, Compos. Sci. Technol., 2006, 66, 1038-1044.

45 G. Goncalves, P. A. A. P. Marques, R. J. B. Pinto, T. Trindade and C. P. Neto, Compos. Sci. Technol., 2009, 69, 1051-1056.

46 I. Chauhan and P. Mohanty, RSC Adv., 2014, 4, 57885-57890.

47 I. Chauhan and P. Mohanty, Cellulose, 2015, 22, 507-519.

48 Y. Li, L. Cao, L. Li and C. Yang, J. Hazard. Mater., 2015, 289, 140-148.

49 S. Sivakumar, P. K. Pillipa, P. Mukundan and K. G. K. Warrier, Mater. Lett., 2002, 57, 330-335.

50 J. Gu, J. M. Catchmark, E. Q. Kaiser and D. D. Archibald, Carbohydr. Polym., 2013, 92, 1809-1816.

51 X. Chen and S. S. Mao, Chem. Rev., 2007, 107, 2891-2959.

52 U. Diebold, Surf. Sci. Rep., 2003, 48, 53-229.

53 C. Couteau and L. Coiffard, Cosmetics, 2015, 2, 394-408.

54 C. B. Detoni, K. Paese, R. C. R. Beck, A. R. Pohlmann and S. S. Guterres, in Nanocosmetics and nanomedicines: New Approaches for Skin Care, ed. R. C. R. Beck, S. S. Guterres and A. R. Pohlmann, Springer-Verlag, Berlin Heidelberg, 1st edn, 2011, ch. Nanosized and Nanoencapsulated Sunscreens, pp. 355-356.

55 S. Arditty, C. P. Whitby, B. P. Binks, V. Schmitt and F. LealCalderon, Eur. Phys. J. E, 2003, 11, 273-281.

56 S. Zakaria, Mater. Chem. Phys., 2004, 88, 239-243.

57 D. Aoki and Y. Nishio, Cellulose, 2010, 17, 963-976.

58 R. Beranek and H. Kisch, Photochem. Photobiol. Sci., 2008, 7, 40-48.

59 J. A. Navio, G. Colon, M. Macias, C. Real and M. I. Litter, Appl. Catal., A, 1999, 177, 111-120.

60 R. L. Penn and J. F. Banfield, Am. Mineral., 1998, 83, 10771082.

61 K. C. Sole, Hydrometallurgy, 1999, 51, 239-253.

62 R. Wu, Y. Wei and Y. Zhang, Mater. Res. Bull., 1999, 34, 21312135. 